Conrado de Oliveira GAMBA $^{1}$

Tiane Ferreira de CASTRO ${ }^{1}$

Eduardo Madruga RICKES ${ }^{2}$

Malcon Andrei Martinez

PEREIRA $^{3}$

\section{Correspondência para:}

Malcon Andrei Martinez Pereira

E-mail: malcon.pereira@ufpel.edu.br

Rua Padre Anchieta, 4715 - 104K

Centro, 96015-420 - Pelotas, RS

Recebido para publicação: 24/11/2005 Aprovado para publicação: 23/04/2007

\title{
Sistematização dos territórios nervosos do plexo braquial em chinchila (Chinchilla lanigera)
}

\author{
1- Faculdade de Veterinária, Universidade Federal de Pelotas, Pelotas - RS \\ 2- Médico Veterinário Autônomo \\ 3- Departamento de Morfologia, Instituto de Biologia, Universidade Federal de Pelotas, \\ Pelotas - RS
}

\section{Resumo}

Para a realização do estudo referente ao plexo braquial (PB) e territórios nervosos do membro torácico de chinchila (Chinchilla lanigera) foram utilizados 10 animais de sete a 11 meses de idade. Tendo a pele sido retirada, procedeu-se a identificação da musculatura do membro torácico, região peitoral e parede torácica e abdominal. Subseqüentemente, foram aplicadas compressas de solução de ácido acético glacial 3\% nas referidas regiões, com o intuito de melhorar a visualização dos nervos. Nos animais analisados notou-se a emergência do PB a partir do sexto nervo cervical até o primeiro torácico. Destas quatro raízes se formam os troncos dos nervos cujos ramos ventrais constituirão seu arranjo e distribuição territorial. Destes quatro troncos surgem os 12 nervos que constituem o PB, estes podem ser formados por apenas um segmento medular: unissegmentar (supraescapular, peitoral cranial e toracodorsal) ou por mais de dois segmentos: plurissegmentar (subescapular, axilar, músculo-cutâneo, torácico lateral, peitoral caudal, torácico longo, mediano, ulnar e radial). Com isso se observou constância na origem, inervação da musculatura, articulações e ossos do membro torácico, podendo-se afirmar a existência de um padrão claramente definido na delimitação dos territórios nervosos.

\section{Introdução}

A chinchila, roedor pertencente à família Chinchillidae, é oriunda da Cordilheira dos Andes no Peru, Chile, Bolívia e Argentina. Possui intensa pelagem sedosa de cor cinzenta com reflexos prateados, o que despertou grande interesse comercial no mercado internacional. Assim, os criatórios têm-se expandido mundialmente, contudo o início de sua exploração quase determinou a extinção desta espécie. Este animal possui em média $26 \mathrm{~cm}$ de comprimento e 14 de espessura, sendo as fêmeas maiores e mais pesadas do que os machos, com quatro patas dismórficas (membros torácicos maiores que os pélvicos). De hábitos alimentares vegetarianos, que inclui basicamente sementes e vegetais, pode viver até 20 anos de idade.

Embora a criação de chinchilas se encontrar em expansão, principalmente no estado do Rio Grande do Sul, há poucos estudos sobre a anatomia desta espécie. Nos atendimentos prestados por Médicos Veterinários é comum estes animais serem erroneamente comparados a outras espécies. Verificando esta lacuna, o Projeto de Ensino: Treinamento em Técnicas Anatômicas desenvolvido no Departamento de Morfologia da Universidade Federal de Pelotas, passou a desenvolver estudos que visam fornecer dados sobre a anatomia da chinchila. Estudos enfocando a sistematização da veia porta e descrição do aparelho digestório ${ }^{1,2}$, aparelho respiratório ${ }^{3} \mathrm{e}$ aspectos da inervação pélvica ${ }^{4}$ vêm fornecendo importantes subsídios para os profissionais envolvidos na criação deste roedor. Neste sentido, o presente trabalho descreve a origem, organização e distribuição da inervação do membro torácico da 
chinchila, através de um estudo macroscópio, em busca de novas descrições sobre espécies exóticas.

\section{Material e Método}

Para o estudo utilizou-se 10 chinchilas (Chinchilla lanigera), cinco machos e cinco fêmeas, com idade variando entre sete e 11 meses, oriundas de criatórios no município de Pelotas, Rio Grande do Sul, que disponibilizaram a carcaça dos animais enfermos e abatidos para a comercialização. De posse destes, conservaram-se os espécimes em solução aquosa de formol $10 \%$, posteriormente retirou-se a pele e os músculos que recobrem a emergência dos nervos espinhais através dos forames intervertebrais com o intuito de melhor observação da origem dos nervos constituintes do plexo braquial (PB). Visando a maximização da visualização de estruturas nervosas foram aplicadas compressas de ácido acético $3 \%$ tendo em vista que a substância provoca a dilatação das bainhas que recobrem o tecido nervoso. Passado o período de 15 minutos necessários à atuação da solução na estrutura, os animais foram lavados em água corrente para que houvesse a preservação da integridade dos nervos constituintes do PB. Após esse espaço de tempo iniciou-se a dissecação bilateral dos constituintes a olho nu e com estereolupa, utilizada para a observação minuciosa da origem das estruturas formadoras dos diferentes componentes do PB, bem como junções entre elas. Finalizando o trabalho foram confeccionados esquemas fotográficos das peças dissecadas, que tinham por objetivo documentar visualmente os resultados obtidos. Os termos utilizados em nossa pesquisa tiveram como base a Nomina Anatômica Veterinária ${ }^{5}$ e, para os termos particulares de roedores, foram citadas as designações de $\mathrm{POPESKO}^{6}$ para coelhos.

\section{Resultados}

$\mathrm{Na}$ chinchila (Chinchilla lanigera) o plexo braquial é constituído pelos ramos ventrais do sexto $\left(\mathrm{C}_{6}\right)$, sétimo $\left(\mathrm{C}_{7}\right)$ e oitavo $\left(\mathrm{C}_{8}\right)$ nervos cervicais e primeiro torácico $\left(\mathrm{T}_{1}\right)$ (Figura 1), essa distribuição é constante nesta espécie. A emergência do PB surge a partir de segmentos medulares formando troncos nervosos de mesmo número. Os dois primeiros troncos deixam o canal vertebral cranialmente às vértebras correspondentes enquanto o terceiro e o quarto o fazem caudalmente às vértebras correspondentes. Seguindo sua trajetória o PB atravessa os músculos longos do pescoço e escaleno (rebatidos para melhor visualização) se direcionando até o espaço axilar onde passa para a região medial do membro torácico, região peitoral e parede torácica. Destes quatro troncos nervosos surgirão doze nervos que suprirão os músculos, ossos, articulações e pele do membro torácico, além de músculos peitorais e parede torácica. Assim podemos inferir que existem somente três nervos unisegmentares, os outros nove nervos se apresentam na forma plurisegmentar (dois ou mais segmentos medulares). Deste ponto em diante passaremos a discutir cada nervo do PB em separado.

Os nervos peitorais na chinchila apresentam-se divididos em peitoral cranial e peitoral caudal. Observamos o nervo peitoral cranial apresentando sua origem a partir de $\mathrm{C}_{7}$ e o nervo peitoral caudal (Figura 2) a partir de $\mathrm{C}_{8}$ e $\mathrm{T}_{1}$. Os nervos peitorais têm como função suprir a musculatura peitoral do animal (músculos peitoral superficial e profundo).

O nervo supraescapular (Figura 1) possui como origem $\mathrm{C}_{6}$, passando pela incisura escapular e suprindo a musculatura do terço proximal do membro (músculos supraespinhal, infraespinhal e a parte acromial do deltóide) sendo acompanhado pelos vasos escapulares em seu trajeto. $\mathrm{Na}$ mesma região, porém na face medial, encontra-se o nervo subescapular (Figura 1) que emerge de $\mathrm{C}_{6}$ e $\mathrm{C}_{7}$, o que o faz plurissegmentar. Este nervo supre a musculatura cranial do membro torácico (músculos subescapular e redondo maior).

Existem três nervos relacionados com as estruturas formadoras da parede lateral do 
tórax, sendo estes: nervo toracodorsal que tem origem de $\mathrm{C}_{8}$, seguindo paralelamente aos vasos toracodorsais e se direciona até a musculatura dorso lateral da parede torácica (músculo grande dorsal); nervo torácico lateral (Figura 1) se origina no oitavo segmento medular cervical e no primeiro torácico, emite ramos chamados intercostobraquiais que são responsáveis pela sensibilidade cutânea da parede ventral torácica e abdominal e pela motilidade do músculo cutâneo do tronco; e o nervo torácico longo (Figura 1) que é proveniente de $\mathrm{C}_{7}$ e $\mathrm{C}_{8}$ e após a anastomose das raízes que o formam, corre superficialmente junto ao músculo serrátil ventral suprindo-o.

A origem aparente do nervo axilar (Figuras 1 e 2) se dá a partir de $\mathrm{C}_{6}$ e $\mathrm{C}_{7}$, cuja união das raízes que originam este nervo formam a alça axilar, responsável por oferecer suporte e sustentação à artéria axilar. Este nervo supre parte da musculatura da

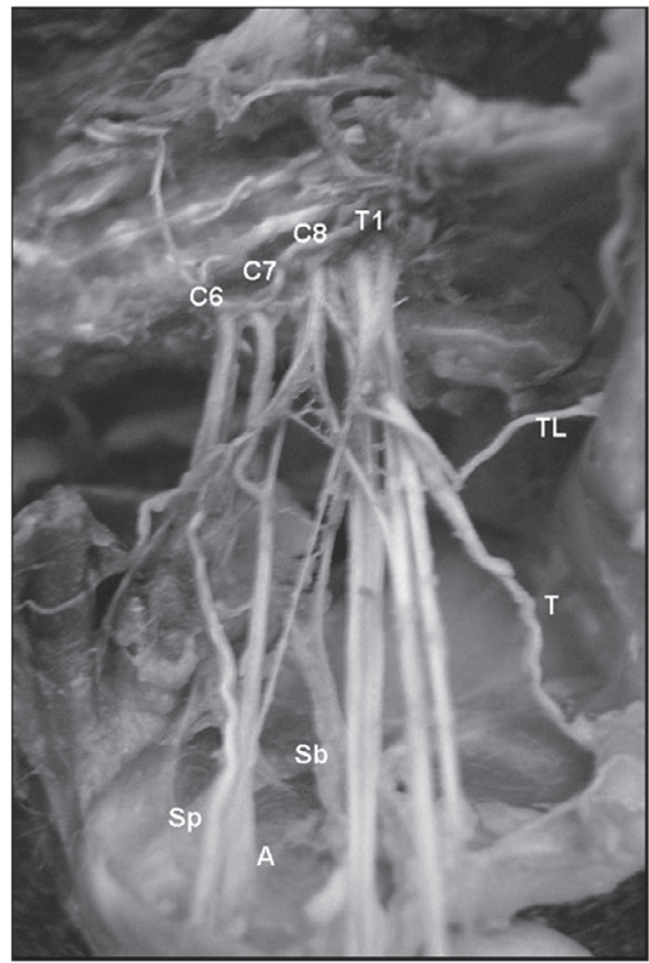

Figura 1 - Fotografia do membro torácico direito da chinchila em vista medial, evidenciando a origem do plexo braquial a partir do sexto $\left(C_{6}\right)$, sétimo $\left(C_{7}\right)$ e oitavo $\left(C_{8}\right)$ nervos cervicais e primeiro $\left(\mathrm{T}_{1}\right)$ torácico. Observamos ainda os nervos: supraescapular (Sp), subescapular (Sb), axilar (A), torácico lateral (TL) e toracodorsal (T) articulação do úmero (músculos redondo maior, parte escapular do deltóide e a porção caudal do músculo subescapular) e o músculo braquiocefálico cleidobraquial. Ainda emite ramos que inervam a fáscia e a pele da região ante-braquial.

Sendo plurisegmentar na chinchila, o nervo ulnar (Figura 2) possui sua origem em $\mathrm{C}_{7}, \mathrm{C}_{8}$ e $\mathrm{T}_{1}$, sua emergência localiza-se paralelamente ao nervo mediano e músculocutâneo, tendo em direção oposta à sua, o nervo peitoral caudal. Ao originar-se, o nervo ulnar está em situação superficial, chegando ao olecrano, muda sua rota e faz o suprimento da musculatura flexora da articulação do carpo (músculos flexor ulnar do carpo e interósseo) e do dígito (músculo flexor digital profundo), além disto, ainda supre a região cutânea ante-braquial caudal com o nervo cutâneo de mesmo nome e a região cutânea digital palmar e lateral.

O nervo mediano (Figura 2) possui origem em $\mathrm{C}_{7}, \mathrm{C}_{8}$ e $\mathrm{T}_{1}$, sendo a mesma do

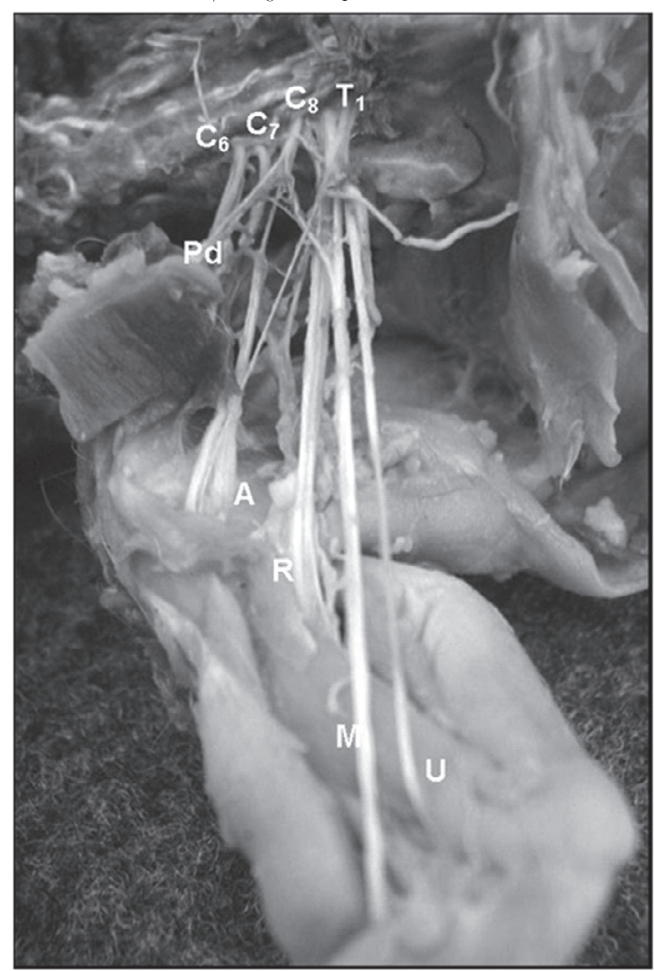

Figura 2 - Fotografia reforçando a origem do plexo braquial a partir do sexto $\left(C_{6}\right)$, sétimo $\left(C_{7}\right)$ e oitavo $\left(C_{8}\right)$ nervos cervicais e primeiro $\left(\mathrm{T}_{1}\right)$ torácico. Também são indicados os nervos: peitoral caudal $(\mathrm{Pd})$, axilar $(\mathrm{A})$, radial $(\mathrm{R})$, mediano $(\mathrm{M})$ e ulnar $(\mathrm{U})$. Vista medial do membro torácico direito 
nervo ulnar, determinando a formação de um tronco comum de emissão destes nervos. Em seu trajeto, ao nível da articulação do úmero esta junção se desfaz e o nervo mediano segue cranialmente ao olécrano com o intuito de alcançar a musculatura flexora do carpo (músculo flexor radial do carpo), o músculo pronador redondo e os músculos flexores do dígito 3 e 4, além de suprir a região cutânea digital palmar e medial.

Partindo da confluência de $\mathrm{C}_{6}$ e $\mathrm{C}_{7}$, está o nervo mùsculo-cutâneo, é proveniente da separação de um tronco comum dos nervos axilar e subescapular. $\mathrm{Na}$ altura da articulação do úmero há a divisão do nervo em dois ramos: o ramo proximal, que inerva a região proximal do músculo biceps braquial e o ramo distal que inerva a região distal do músculo bíceps braquial e o músculo braquial, se direcionando para a inervação da pele na região ante-braquial medial através do nervo cutâneo ante-braquial medial. Ainda foi possível observar uma conexão deste ultimo ramo com o nervo mediano, logo abaixo da divisão em ramos do nervo músculo-cutâneo.

O nervo radial (Figura 2) é o terceiro componente do $\mathrm{PB}$ que apresenta três raízes, este provém de $\mathrm{C}_{7}, \mathrm{C}_{8}$ e $\mathrm{T}_{1}$ e próximo à articulação do úmero seu trajeto está intimamente relacionado com a artéria axilar. Apesar de originar-se medialmente, nesta região imerge na musculatura se deslocando distalmente até a região lateral do membro onde se ramifica triplamente. Este nervo envia ramos aos músculos: ancôneo, tríceps braquial, braquial, tensor da fáscia antebraquial, extensor oblíquo do carpo, radial do carpo, ulnar do carpo, extensores digitais, comum e lateral, oblíquo longo e os supinadores longo e breve. Também contribui na inervação cutânea da região antebraquial cranial e lateral e da região digital dorsal e lateral.

\section{Discussão}

$\mathrm{Na}$ intumescência cervical surgem raízes dorsais e ventrais que se unem formando o tronco do nervo espinhal. A partir do tronco deste nervo ocorre a emissão de ramos somáticos e viscerais, dos quais os primeiros, através de um ramo ventral, constituem o plexo braquial $(\mathrm{PB})^{7}$. A origem constante do PB na chinchila (Chinchilla lanigera) é semelhante à descrita para espécies domésticas como o cão ${ }^{8,9,10}$ e o gato ${ }^{11,12}$, assim como para o lobo-marinho ${ }^{13}$. Entretanto, é importante salientar que nestas duas espécies pode ocorrer a presença de ramos contribuintes oriundos de $\left(\mathrm{C}_{5}\right.$ e $\left.\mathrm{T}_{2}\right)$. Em comparação a outros roedores, a origem do $\mathrm{PB}$, bem como suas ramificações e territórios de inervação, são extremamente variados. Em ratos (Mus novergicus albinus), Greene ${ }^{14}$ descreveu que o plexo tem origem a partir do segmento $C_{5}$ até $T_{1}$ e, algumas vezes, o segundo torácico. $\mathrm{Na}$ capivara (Hidrochaeris Hidrochaeris) ele é constituído por $\mathrm{C}_{4}, \mathrm{C}_{5}, \mathrm{C}_{6}$, $\mathrm{C}_{7}, \mathrm{C}_{8}$ e $\mathrm{T}_{1}{ }^{15}$, havendo variações de um animal para outro. Nos mocós (Kerodon Rupestres) o PB forma-se do $\mathrm{C}_{6}, \mathrm{C}_{7}, \mathrm{C}_{8}, \mathrm{~T}_{1} \mathrm{e}$ $\mathrm{T}_{2}$, podendo em algumas ocasiões haver a participação de $\mathrm{C}_{5}$, também se observou neste animal que de $\mathrm{C}_{6}, \mathrm{C}_{7}, \mathrm{C}_{8}, \mathrm{~T}_{1}$ sempre estão contribuindo na formação do $\mathrm{PB}^{16}$.

Em comum, a todas as referências consultadas, esta a localização ou surgimento do PB junto aos músculos longo do pescoço e escaleno e seu direcionamento até o espaço axilar. Assim como a formação de troncos que originarão nervos uni e plurisegmentares, o número de nervos é bastante variável. Enquanto que na chinchila, capivara ${ }^{15}$, cão $^{8,9,10}$, gato $^{11,12}$, e lobo-marinho ${ }^{13}$ são descritos doze nervos compondo o plexo, nos ratos Greene ${ }^{14}$ descreveu a presença de um nervo escapular oriundo de $\mathrm{C}_{5}$. Nas chinchilas observa-se a existência de três nervos unissegmentares, os outros nove nervos se apresentam na forma plurissegmentar (dois ou mais segmentos medulares). Esta descrição quanto ao número de nervos uni e plurissegmentares coincide com a do lobo-marinho ${ }^{13}$. Contudo, observa-se que em cães ${ }^{8}$, gatos ${ }^{11,12}$ e capivaras ${ }^{15}$ tal ocorrência é divergente, sendo importante ressaltar que nesta última espécie todos os ramos são plurissegmentares.

Existe concordância sobre a existência 
de nervos peitorais craniais e caudais $8,11,12,13,14,15,17$. Entretanto em relação aos seus segmentos de origem, ressalta-se que em ratos $^{14}$ o primeiro surge de $\mathrm{C}_{5}$ e $\mathrm{C}_{6}$ e o segundo de $\mathrm{C}_{7}$, enquanto que em lobomarinho o primeiro se origina de $\mathrm{C}_{6}{ }^{13}$. Já no cão todos os quatro principais segmentos que dão origem ao $\mathrm{PB}$ têm participação na formação dos nervos peitorais ${ }^{8,9,10}$. Em gatos ocorre de maneira muito análoga, porém com a ausência de $\mathrm{C}_{6}^{11,12}$. Já na capivara o nervo peitoral caudal é substituído pelo nervo torácico lateral que com sua porção caudal supre o músculo peitoral profundo ${ }^{15}$.

A observação da origem aparente do nervo supraescapular vai ao encontro com a descrição para gatos ${ }^{11,12}$. Entretanto no cão $\mathrm{O}^{8,9,10}$ e no lobo-marinho ${ }^{13} \mathrm{o}$ mesmo é plurissegmentar, tendo origem em $\mathrm{C}_{6}$ e $\mathrm{C}_{7}$. Ambos os autores relatam a união destes nervos através de uma alça dupla cujo ramo mais caudal é muito delgado. $\mathrm{Na}$ capivara sua origem varia entre $\mathrm{C}_{4-6}$ e $\mathrm{C}_{5-7}{ }^{15}$. Já em ratos, Greene $^{14}$ afirma que sua origem provém de $\mathrm{C}_{5}$ e $\mathrm{C}_{6}$. De acordo com Crouch ${ }^{17}$, no gato, este nervo pode enviar ramos para o nervo subescapular.

Apesar de manter seu caráter plurissegmentar e a mesma origem descrita para o cão e o gato ${ }^{12,18}$, o nervo subescapular, apresenta uma grande gama de descrições entre as espécies. Em lobo-marinho provém apenas de $\mathrm{C}_{7}$ sendo, portanto, unissegmentar neste animal ${ }^{13}$ e segundo Reimers ${ }^{11}$ quando há apenas um nervo subescapular no cão, como se vê no lobo-marinho, este pode surgir no sétimo segmento medular cervical. $\mathrm{Na}$ capivara, Fioretto et. al. ${ }^{15}$, observaram a divisão deste nervo em ramo cranial e caudal, quanto à origem ele provém de $\mathrm{C}_{5}$ e $\mathrm{C}_{6}$ ou de $\mathrm{C}_{5}, \mathrm{C}_{6}$ e $\mathrm{C}_{7}$, sendo esta última a mesma descrição encontrada em ratos ${ }^{14}$.

Muito evidentes são as características dos três nervos relacionados com a parede torácica, assim como as variações encontradas na literatura consultada. O nervo toracodorsal tem origem semelhante no cão ${ }^{9,10}$. Diferindo do descrito para lobomarinho ${ }^{13}$ e gato ${ }^{17}$, onde no primeiro sua procedência é de $\mathrm{C}_{6}$; já no segundo ocorre a partir de $\mathrm{C}_{7}{ }^{11,12}$. Na capivara a origem deste nervo se forma a partir dos segmentos $\mathrm{C}_{6}$, $\mathrm{C}_{7}, \mathrm{C}_{8}$ e $\mathrm{T}_{1}$ ou $\mathrm{C}_{6}, \mathrm{C}_{7}$ e $\mathrm{C}_{8}{ }^{15}$, enquanto que em ratos ${ }^{14}$ ocorre de $\mathrm{C}_{6}$ e $\mathrm{C}_{7}$, em conjunto com o nervo axilar. Como no gato ${ }^{12} \mathrm{e}$ no lobo-marinho ${ }^{13} \mathrm{o}$ nervo torácico lateral na chinchila surge de $\mathrm{C}_{8}$ e $\mathrm{T}_{1}$. Já se tratando do cão, sua origem diverge contendo três segmentos medulares: $\mathrm{C}_{8}, \mathrm{~T}_{1}$ e $\mathrm{T}_{2}{ }^{8,9,10} . \mathrm{Na}$ capivara, o nervo tem origem em $\mathrm{C}_{6}$ e $\mathrm{C}_{7}$ ou $\mathrm{em} \mathrm{C}_{7} \mathrm{e} \mathrm{C}_{8}{ }^{15}$. Sua origem é mais cranial em ratos $^{14}$, estando entre $\mathrm{C}_{5}$ e $\mathrm{C}_{6}$.

Dos três nervos torácicos o mais constante é o nervo torácico longo, ocorrendo de modo semelhante ao descrito para lobo-marinho ${ }^{13}$, capivara $^{15}$ e cães ${ }^{8,9,10}$. O mesmo não é válido para o gato, pois este tem sua origem em $\mathrm{C}_{7}{ }^{12,18}$ assim vê-se que neste animal o nervo é unissegmentar e diverge dos demais animais em discussão. Todavia nas capivaras, além da origem que vai de encontro com as espécies acima, podese observar uma procedência de $\mathrm{C}_{6}$ e $\mathrm{C}_{7}{ }^{15}$. Também em ratos é descrito uma origem a partir de $\mathrm{C}_{6}$ a $\mathrm{C}_{8}$, diferente do encontrado em nossas dissecações.

A origem aparente do nervo axilar se dá a partir de $\mathrm{C}_{6} \mathrm{e}_{7}$, sendo convergente ao descrito para ratos ${ }^{14}$ e gatos ${ }^{11,12}$. Entretanto no cão $\mathrm{O}^{8,9,10}$ e no lobo-marinho ${ }^{13}$ este é proveniente de $\mathrm{C}_{7}$ e $\mathrm{C}_{8}$. Na capivara a origem aparente foi relatada a partir de $\mathrm{C}_{5}$ e $\mathrm{C}_{6}$ ou de $\mathrm{C}_{6}, \mathrm{C}_{7}$ e $\mathrm{C}_{8}{ }^{15}$. É também a partir da união das raízes que originam este nervo que se forma a alça axilar, ${ }^{90114}$.

A existência de um tronco comum de origem para os nervos ulnar e mediano é descrita no rato ${ }^{14}$, cão $^{8,9,10}$ e gato $^{11,12}$, sem que ocorra a participação dos nervos músculocutâneo e peitoral, como ocorre no lobomarinho ${ }^{13}$. Sendo plurissegmentar em todas as espécies confrontadas, o nervo ulnar tem origem semelhante no gato ${ }^{11,12}$. No rato ${ }^{14}$, cão ${ }^{8,9,10}$ e no lobo-marinho ${ }^{13}$ difere pela supressão de $\mathrm{C}_{7}$. Já na capivara, de uma forma discrepante, possui sua origem de $\mathrm{C}_{6}$, $\mathrm{C}_{7}, \mathrm{C}_{8}$ e $\mathrm{T}_{1}$ ou $\mathrm{C}_{6}, \mathrm{C}_{7} \mathrm{e} \mathrm{C}_{8}{ }^{15}$. O nervo mediano possui a mesma origem do nervo ulnar, igualmente à descrita para o gato ${ }^{11,12}$, divergindo do rato, cão e lobo-marinho que 
tem sua formação a partir de $\mathrm{C}_{8}$ e $\mathrm{T}_{1}^{8,13,14}$, assim como na capivara, onde parte de $\mathrm{C}_{6}$ até $\mathrm{T}_{1}{ }^{15}$

O nervo músculo-cutâneo separa-se de um tronco comum aos nervos axilar e subescapular, o que confirma a grande incidência de semelhança entre o gato ${ }^{11,12} \mathrm{e}$ a chinchila. Quando comparamos a chinchila com o cão, temos a descrição de que, no segundo, o nervo provém de $\mathrm{C}_{6-7}$ ou $\mathrm{C}_{7-8}{ }^{8}$. Da mesma forma com o lobo-marinho, onde parte de $\mathrm{C}_{8} \mathrm{e} \mathrm{T}_{1}{ }^{13}$. Este nervo em ratos possui a mesma origem que o nervo subescapularmaior, partindo desde $\mathrm{C}_{5}$ e $\mathrm{C}_{7}$ 14. As características de divisão em ramos proximal e distal, bem como seus territórios são semelhantes em todas as espécies.

O nervo radial é o terceiro componente do PB que apresenta três raízes, este provém de $\mathrm{C}_{7-8}$ e $\mathrm{T}_{1}$, é organizado da mesma forma no gato, no lobo-marinho e nos cães ${ }^{8,11,12,13}$. No entanto no cão pode haver em algumas situações a adição de $\mathrm{T}_{2}{ }^{8}$. Quando comparado com a capivara, observamos uma discrepância, já que nesta espécie tem origem de $\mathrm{C}_{6-8}$ e $\mathrm{T}_{1}$, ou seja, de todas as raízes que formam o plexo. Já em ratos ${ }^{14}$, este nervo forma-se dos segmentos $\mathrm{C}_{6} \mathrm{a} \mathrm{C}_{8}$, mantendo suas demais características semelhantes às demais espécies.

\section{Conclusões}

Ao término de nosso trabalho, através do material obtido pelas dissecações e das observações efetivadas, conseguimos obter resultados que nos permitiram sistematizar os territórios nervosos da Chinchilla lanigera, com isso podemos concluir que:

1. $\mathrm{O} P B$ se origina dos ramos ventrais somáticos dos nervos espinhais do $\mathrm{C}_{6}, \mathrm{C}_{7}, \mathrm{C}_{8}$ e $\mathrm{T}_{1}$;

2. Variações quanto à contribuição de outros nervos espinhais na formação do plexo não foram observadas;

3. Dos quatro troncos que dão origem ao plexo são formados doze nervos, sendo dentre estes, três unissegmentares e nove plurissegmentares;

4. Os nervos unissegmentares são: supraescapular $\left(\mathrm{C}_{6}\right)$, peitoral cranial $\left(\mathrm{C}_{7}\right)$ e toracodorsal $\left(\mathrm{C}_{8}\right)$;

5. O nervo radial apresenta o maior território muscular, dentre os componentes do PB;

6. Os nervos ulnar, mediano e radial possuem o maior número de troncos constituintes, sendo derivadas fibras ventrais de $\mathrm{C}_{7}, \mathrm{C}_{8}$ e $\mathrm{T}_{1}$;

7. A partir dos ramos ventrais de $\mathrm{C}_{8} \mathrm{e}$ $\mathrm{T}_{1}$ é formado um tronco comum que dá origem aos nervos: peitoral caudal e torácico lateral;

8. De $\mathrm{C}_{6}$ e $\mathrm{C}_{7}$ surgem os nervos subescapular, axilar e músculo-cutâneo;

9. Surgindo de $\mathrm{C}_{7}$ e $\mathrm{C}_{8}$ temos apenas o nervo torácico longo;

10. Quanto aos territórios de inervação não foram observadas variações em relação à literatura consultada.

\section{The nervous territories of the brachial plexus in Chinchilla lanigera}

\section{Abstract}

For the study concerning the Brachial Plexus (BP) and nervous territories of chinchillas (Chinchilla lanigera) 10 animals were used. After the removal of the skin, the indetification of the thoracic limb, pectoral area and thoracic and abdominal walls was made. Then, compresses of glacial acetic acid at 3\% were applied to these areas, in order to improve the observation of the nerves. In the studied animals, the emergence of the BP was observed to be from the sixth cervical nerve to the first thoracic nerve. These four roots make the trunks of the nerves whose ventral branches constitute their arrange and territorial distribution. From these four trunks
Key words: Innervation. Brachial plexus. Chinchilla. Anatomy. 
arise the 12 nerves that constitute the BP. These nerves may be formed by a single medullary segment - monosegmentar (suprascapular, cranial pectoral, thoracodorsal), or by two ou more segments, plurisegmentar (subscapular, axillary, musculocutaneous, lateral thoracic, caudal pectoral, long thoracic, median, ulnar and radial). Therefore, constancy in origin, muscle, joint and bone innervation was observed, and can confirm the existence of a clearly defined pattern of the delimitation of nervous territories.

\section{Referências}

1 CASTRO, T. F. et al. Aspectos morfológicos, morfométricos e topográficos do aparelho digestório de Chinchilla lanígera. In: SALÃO DE INICIAÇÃO CIENTíFICA, 17., 2005, Porto Alegre. Anais...Porto Alegre: Universidade Federal do Rio Grande do Sul, 2005.

2 CASTRO, T. F. et al. Formação e tributárias da veia porta em Chinchilla lanígera. In: CONGRESSO DE INICIAÇÃO CIENTífICA, 13., 2004, Pelotas. Anais... Pelotas, Universidade Federal de Pelotas, 2004.

3 PEREIRA, R. L. et al.. Topologia e topografia do aparelho respiratório e árvore brônquica de Chinchilla lanígera. In: SALÃO DE INICIAÇÃO CIENTíFICA, 17. 2005, Porto Alegre. Anais...Porto Alegre: Universidade Federal do Rio Grande do Sul, 2005.

4 RONDINI, B. T. et al. (2005) Sistematização dos territórios nervosos do plexo lombo-sacral em Chinchilla lanígera. In: SALÃO DE INICIAÇÃO CIENTÍFICA, 17. 2005, Porto Alegre. Anais...Porto Alegre: Universidade Federal do Rio Grande do Sul, 2005.

5 INTERNATIONAL COMMITTE ON VETERINARY GROSS ANATOMICAL NOMENCLATURE. Nomina anatomica veterinaria. 4. ed. Zürich, 1994. (Together with nomina histologica, 2. ed., 1992 and nomina embriologica veterinaria, 1992).

6 POPESKO, P. Atlas de anatomia topográfica dos animais domésticos. São Paulo: Manole, 1985. v. 1-3.

7 HILDEBRAND, M. Análise da estrutura dos vertebrados. 1. ed.. São Paulo: Atheneu, 1995.

8 MILLER, M. E.; CHRISTENSEN, G. C.; EVANS, H. E.
Anatomy of the dog. Philadelphia: W. B. Saunders Company, 1964.

9 DYCE, K. M.; SACK, W.O.; WENSING, C. J. G. Tratado de anatomia veterinária. 2. ed. Rio de Janeiro: Guanabara-Koogan, 1987.

10 KÖNIG, H. E.; LIEBICH, H. J. Anatomia dos Animais Domésticos. Porto Alegre: Artmed, 2002, v. 1-2.

11 REIMERS, H. Der Plexus brachialis der Haussäugetire; eine vergleichend-anatomische Studie. Z. Anat., v. 76, p. 653-753, 1925.

12 GHOSHAL, N. G. Sistema nervoso do carnívoro. In: GETTY, R. SISSON \& GROSSMAN: Anatomia dos animais domésticos. 5. ed. Rio de Janeiro: GuanabaraKoogan, 1986.

13 SOUZA, D. A. S. et al. Sistematização do plexo braquial em Arctocephalus australis. In: Congresso de Iniciação Científica, 14., Pelotas. Anais... Pelotas: Universidade Federal de Pelotas.

14 GREENE, E. C. Anatomy of the rat. New York: Hafner Publishing, 1955.

15 FIORETTO, E. T. et al. Gross anatomic organization of the capybara's (Hydrocharis hydrochaeris) brachial plexus. Anat. Histol. Embryol., v. 32, n. 3, p. 169-74, 2003.

16 SANTANA, J. J. et al. Origem do plexo braquial de mocós (Kerodon rupestris wied, 1820). Braz. Journ. Vet. Res. and Anim. Sci., v. 40, p. 391-396, 2003.

$17 \mathrm{CROUCH}$, J. E. Text-atlas of cat anatomy. Philadelphia: Lea \& Febiger, 1969.

18 BARONE, R. Anatomia comparata del mammiferi doméstici. Bologna: Edagircole, 1974. 